\title{
Diurnal Oscillation of the Convective Boundary Layer Part 2: Cloudy Atmosphere
}

\author{
Ching-CHI Wu \\ Department of Atmospheric Sciences \\ National Taiwan University, Taipei, Taiwan, R.O.C. \\ AND \\ WEN-YIH SUN \\ Department of Earth and Atmospheric Sciences \\ Purdue University, West Lafayette, IN 47907, U.S.A.
}

(Received 21 March 1990; revised 28 June 1990)

\begin{abstract}
A simple one-dimensional ensemble average PBL model, including condensation, evaporation, and atmospheric radiation is used to study the evolution of PBL in a cloudy atmosphere. The turbulent kinetic energy $E$ is predicted by the TKE equation. The eddy coefficient is proportional to $\sqrt{E} l$; the length scale $l$ is determined by Sun and Ogura's method. Meanwhile, the similarity equations are used in the surface layer; the force restoring method is adopted to calculate the surface soil temperature and moisture.

The observed fields at 0900 EST on Day 33 in the Wangara Experiment are used for the first 3 hours (to 1200 EST). After that time, the temperature and moisture are modified in order to initiate a cloud layer and then, the model is integrated for 45 hours. The simulated mean fields and eddy fluxes are comparable with other higher-order model and observations.

During the daytime, the linear decreases of $\overline{w^{\prime} \theta_{v}^{\prime}}$ with height in the lower convective layer are consistent with a uniform change of mean temperature within the subcloud layer. A slightly negative heat flux exists near the cloud base and just above the cloud top. A substantial positive heat flux exists in the cloud layer, primarily attributed to the latent heat release and enhanced by the strong radiative cooling. During the night, the heat flux near the surface becomes negative. Like the daytime results, a positive heat flux exists inside the cloud and a negative hea.t flux exists just above the cloud top.
\end{abstract}

\section{INTRODUCTION}

Since the early study of Lilly (1968), there are more and more researchers studying the cloud-topped planetary boundary layer (PBL). The structure of 
the cloud-topped PBL is strongly influenced by radiative cooling/warming, although the vertical distribution of the radiative cooling near the cloud top is controversial (Randall, 1980). Lilly (1968), Schubert(1976), and Kraus and Schaller (1978) assumed that the occurrence of radiative cooling is confined to a infinitestmally thin inversion layer which is located just above the cloud top. On the other hand, Kahn and Businger (1979) assumed that the radiative cooling occurs in the upper part, about $100 \mathrm{~m}$ thick, of the cloud deck. Fravalo et $a l_{\text {. }}$ (1981) claimed that the latter assumption is in better agreement with the observations of Paltridge (1971, 1974), Platt (1976), and Stephens et al. (1978).

In this study, the turbulence model of Sun and Chang (1986) is modified by incorporating a parameterization scheme for radiation. Also, the force restoring method is adopted to calculate the surface soil temperature and moisture. It can be used to simulate the diurnal variation of the PBL in both cloud-free and cloudy atmospheres. The Wangara data on Day 33-35 (Clarke et al., 1971) are used to verify the model for the cloud-free atmosphere (Wu and Sun, 1990). In this paper, the model is used to test the diurnal variation of the cloudtopped PBL. The results are comparable to those produced by the higher-order turbulence schemes and observations. Because of its simplicity, this model has been applied in a two-dimensional mesoscale model to study the diurnal variation of the dryline in the Great Plains of the U.S. (Wu and Sun, 1987).

\section{THE MODEL}

The major prognostic variables in this one-dimensional ensemble average PBL model are equivalent potential temperature $\left(\bar{\theta}_{e}\right)$, total water content (liquid plus vapor) $\left(\bar{q}_{w}=\bar{q}+\bar{q}_{l}\right)$, and two horizontal wind components $(\bar{u}$ and $\bar{v})$. For shallow convection without precipitation, $\theta_{e}$ is a semi-conservative quantity. A prognostic equation is used to predict the turbulent kinetic energy $(\bar{E})$. The eddy fluxes are calculated by the eddy-coefficient method (Deardorff, 1980). The mixing-length scale $l$ is determined by Sun and Ogura's method (1980).

Following Chen and Cotton (1983) for the cloud-free conditions, Rodgers' (1967) parameterization for long-wave radiation, Yamamoto's (1962) parameterization for the absorption of short-wave radiation, and Stephens' method (Chen and Cotten, 1983) for Rayleigh scattering are all utilized in this study. For a cloudy atmosphere, Stephens' (1978) parameterization for long- and shortwave radiation are used.

The surface soil temperature and moisture are determined by the force restoring method (Bhumralkar, 1975; Blackadar, 1976; Deardorff 1978). Detailed descriptions of the model can be found in Wu and Sun (1990).

\section{BOUNDARY AND INITIAL CONDITIONS}




\section{a. Boundary conditions}

The surface wind velocities are assumed to be zero; the temperature and specific humidity at the surface are predicted by the force restoring method. The sensible heat and moisture fluxes at the surface are estimated by the similarity equations proposed by Businger et al. (1971).

At the upper boundary, all the turbulence variables and wind shears are set to zero; the moisture varies only due to vertical advection, and the temperature varies only due to vertical advection and radiative cooling or warming. The vertical gradients of moisture and temperature at the upper boundary are fixed at their initial values.

\section{b. Initial conditions}

Because the observed vertical velocity in the Wangara Experiment is inappropriate for use in the cloudy case, an idealized profile of vertical velocity,

$$
w=-0.002 \tanh \left(4.2857 \times 10^{-3} z\right)
$$

is applied (Fig. 1). This profile is similar to that used in Bougeault (1981), but the maximum value of the downward motion is reduced from $0.8 \mathrm{~cm} \mathrm{~s}^{-1}$ (in Bougeault) to $0.2 \mathrm{~cm} \mathrm{~s}^{-1}$ so that the cloud can grow easily.

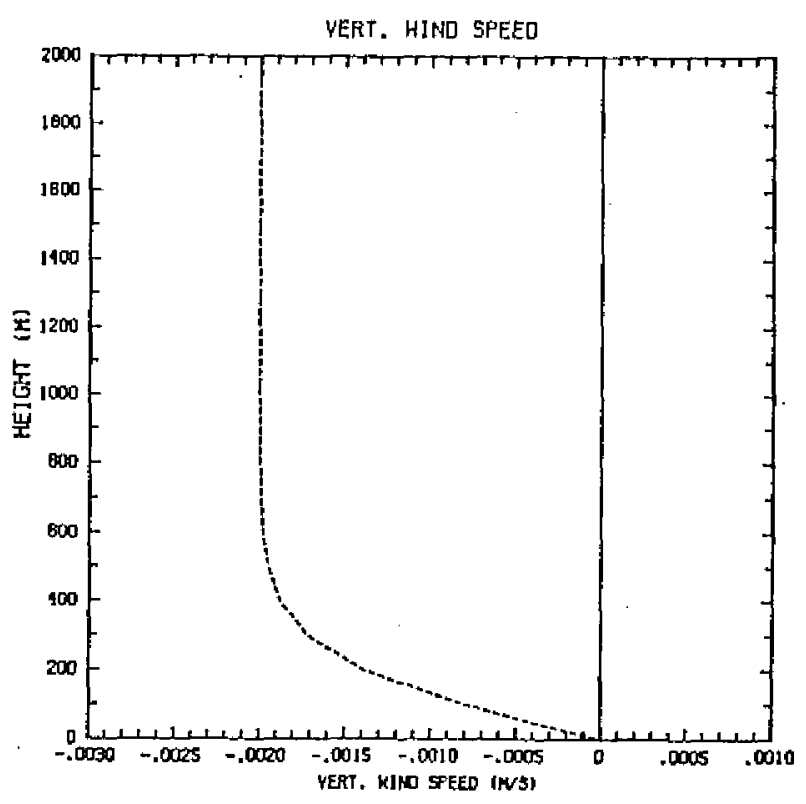

$F i g$. 1. Profile of the vertical velocity. 
The initial values of ground surface moisture $\left(w_{g}\right)$ and average soil moisture $\left(w_{2}\right)$ are set to 0.15 and 0.20 , respectively, and average surface temperature $T_{2}$ is set to $279.6 \mathrm{~K}$. The horizontal wind, temperature, and moisture observed at 0900 EST, Day 33 of the Wangara Experiment (Clarke et al, 1971) are used as initial fields for the first 3 hours (to 1200 EST) of the run. Then, in order to initiate a cloud layer the temperature is decreased by $3 K$ within the mixed layer, while increased by $0.75 K$ above that region. This creates a sharp inversion across the top of the boundary layer. In addition, each layer has its specific humidity increased by $10 \%$ of the saturated specific humidity . After artificial adjustment, the clouds appear and develop continuously. The structures of computed virtual potential temperature, equivalent potential temperature, total water content, and liquid water content, as well as their turbulent fluxes $\overline{w^{\prime} \theta_{v}^{\prime}}, \overline{w^{\prime} q_{w}^{\prime}}$, and $\overline{w^{\prime} q_{l}^{\prime}}$ will be discussed in the next section.

\section{RESULTS AND DISCUSSIONS}

After 1200 EST, DAY 33, the model is integrated for 45 hours (total 48 hours). For convenience, we still use the names Day 33,34 , and 35 , but the environments are quite different from those in the Wangara Experiment.

\section{a. Temperature and heat flux}

The computed profiles of $\bar{\theta}_{v}$ and $\bar{\theta}_{e}$ at 1500 EST and 0300 EST on Day 34-35 are presented in Fig. 2. These structures are as expected. During the daytime, a shallow superadiabatic layer exists near the ground surface; where as during the night, this superadiabatic layer is replaced by a nocturnal surface inversion. A well-mixed subcloud layer, characterized by neutrally to slightly unstable stratification, is located above the shallow superadiabatic or surface inversion layer. Within the cloud layer, the lapse rate is essentially moist adiabatic. Therefore, the virtual potential temperature increases with height within the cloud layer, but the equivalent potential temperature remains constant. The cloud layer is topped by a strong inversion.

In the subcloud layer, the virtual potential temperatures are, respectively, about $279.2,278.6$ and $278.0 K$ at 0000,0300 , and 0600 EST on Day 34 . Therefore, the cooling rate in the subcloud layer during the night on Day 34 is about $0.2 \mathrm{~K} \mathrm{hr}^{-1}$; it is slightly smaller (about $0.16 \mathrm{~K} \mathrm{hr}^{-1}$ ) on Day 35 .

The heat fluxes at 1500 EST on Day 34 and 0300 EST on Day 35 are presented in Fig. 3. During the daytime (1500 EST), the transport of heat from the surface is achieved mainly by the turbulent eddies. The linear decreases of $\overline{w^{\prime} \theta_{v}^{\prime}}$ with height in the lower convective layer are consistent with a uniform increase of mean temperature within the subcloud layer in daytime, which 


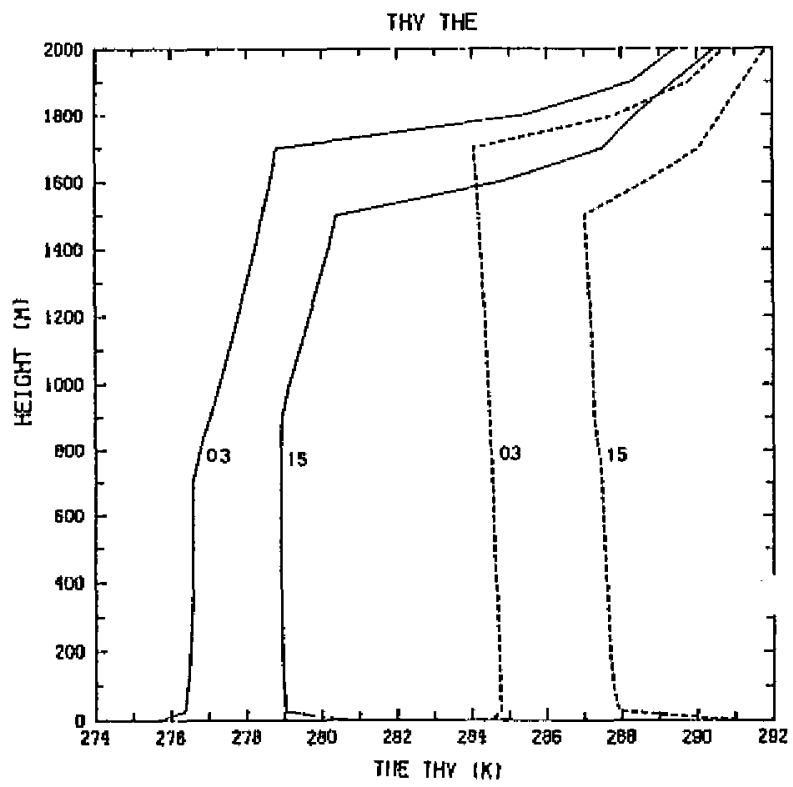

Fig. 2. Profiles of the computed equivalent (solid line) and virtual potential temperature (dashed line) at 1500 FST, Day 34 and 0300 EST, Day 35.

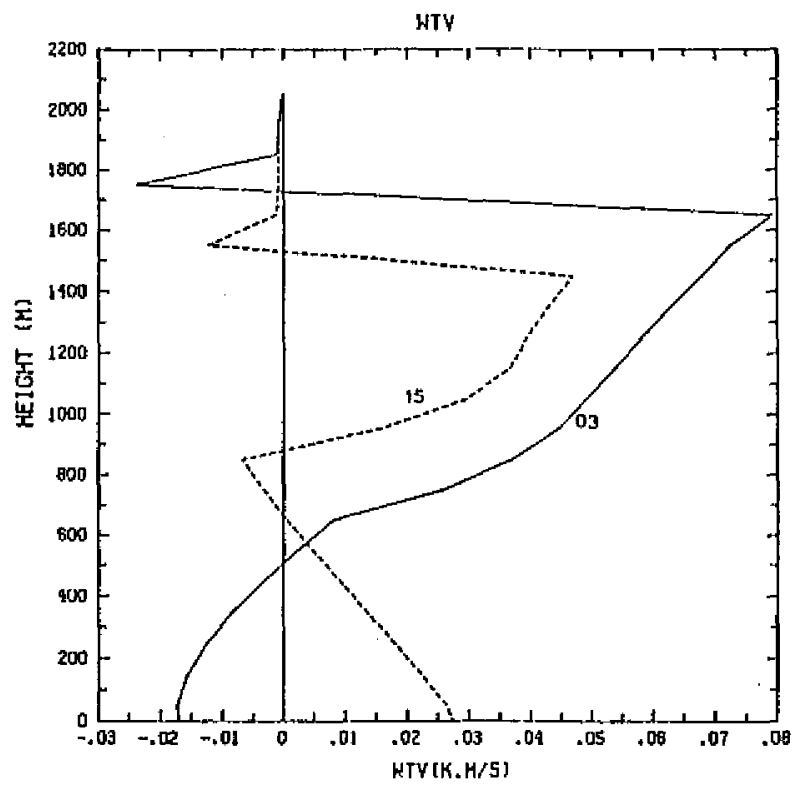

Fig. 3. Profiles of the computed vertical virtual potential temperature flux $\left(\overline{w^{\prime} \theta_{v}^{\prime}}\right)$ at 1500 EST, Day 34 and 0300 EST, Day 35.

is similar to the case in cloud-free atmosphere. As in Sommeria (1976) and Bougeault (1985), there is a slightly negative heat flux near the cloud base due to entrainment. Above this layer, a substantial positive heat flux exists in the 
cloud layer. This is primarily attributed to the release of the latent heat and is enhanced by the strong radiative cooling at the cloud top (Fig. 4). Convection triggered by the the radiative cooling at the cloud top is similar to that produced by the insolation heating at the ground. Thus, the turbulence in the mixed layer can be maintained sufficiently by either one or both of these mechanisms (Deardorff, 1980). The heat flux inside the mixed layer is actually strongly linked to the activity of the cloud (Sommeria, 1976). As the results in Sommeria (1976), Deardorff (1980), Chen and Cotton (1983), and Bougeault (1985), a negative buoyancy flux exists just above the cloud top because of entrainment and diabatic cooling.

During the night (0300 EST), the heat flux near the surface becomes negative. Also, like the daytime, a positive heat flux exists inside the cloud and a negative heat flux exists just above the cloud top. Caughey et al. (1982) deduced from the field study of nocturnal stratocumulus that large positive heat fluxes can be found near the cloud top. The maximum values of the heat flux inside the cloud during the night are larger than those during the daytime, because more water content condenses( see Fig. 4) due to a lower temperature inside the convective boundary layer (CBL), as well as a stronger radiative cooling rate at the cloud top. The long-wave radiative cooling is partially compensated for by the short-wave warming during the daytime.

The heat fluxes above the cloud top are $-0.012 \mathrm{~K} \mathrm{~m} \mathrm{~s}^{-1}$ at $1500 \mathrm{EST}$ on Day 34, and $-0.024 \mathrm{~K} \mathrm{~m} \mathrm{~s}^{-1}$ at 0300 EST on Day 35 (Fig. 3). The magnitudes are smaller than the result (about $-0.03 \mathrm{~K} \mathrm{~m} \mathrm{~s}^{-1}$ ) of case 6 in Deardorff (1980). The observed heat fluxes at the inversion of the marine stratocumulus in Brost et al. (1982) are about $-0.012,-0.008$, and $-0.065 \mathrm{~K} \mathrm{~m} \mathrm{~s}^{-1}$ in different cases, respectively.

\section{b. Moisture and moisture flux}

The total specific humidity (solid line) and specific liquid water content (dashed line) at 1500 EST, Day 34 and 0300 EST, Day 35 are shown in Fig. 4. As expected, the liquid water content increases with height inside the cloud because of a lower temperature near the cloud top. In the mixed layer, the $\bar{q}_{w}$ decreases very slightly with height, as for the cloud-free case. During the daytime, the turbulence within the cloud layer is primarily maintained by the latent heat release, but in the subcloud layer is mainly maintained by the surface heat flux. The cloud base is the interface of these two mechanisms. Like observations of nocturnal stratocumulus in Roach et al. (1982) and Bougeault(1985) (Figs. 5 and 6), the profile of $\bar{q}_{w}$ at 0300 EST on Day 35 shows $\bar{q}_{w}$ slightly decreases with height from ground to cloud top; the slope of $\bar{q}_{w}$ is steepest in the stable surface layer. In Fig. 6 (Roach et al., 1982), if the liquid water content is added 


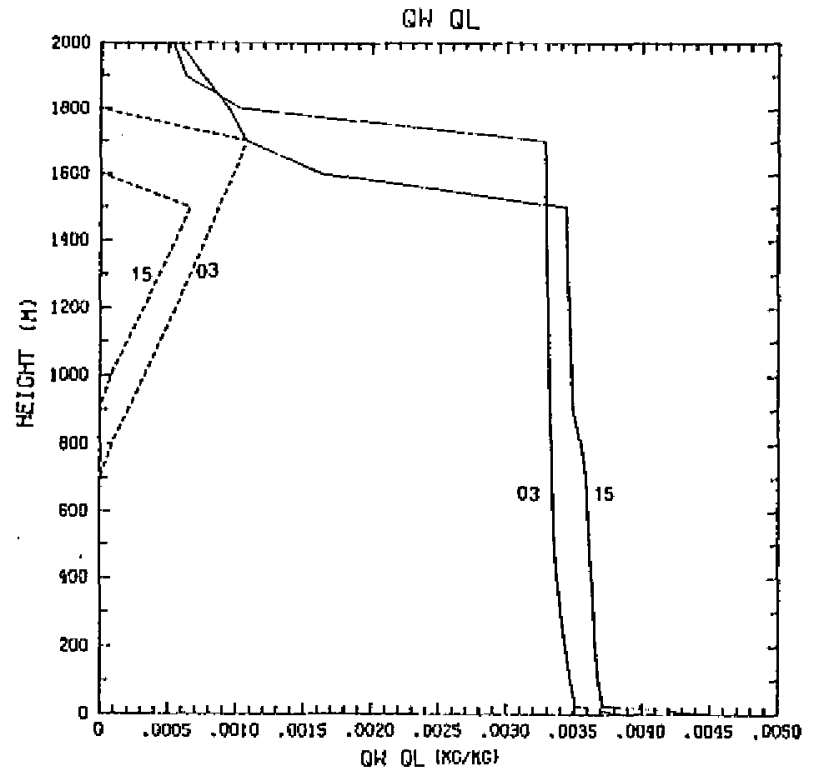

Fig. 4. Profiles of the computed total specific humidity (solid line) and specific liquid water content (dashed line) at 1500 EST, Day 34 and 0300 EST, Day 35.

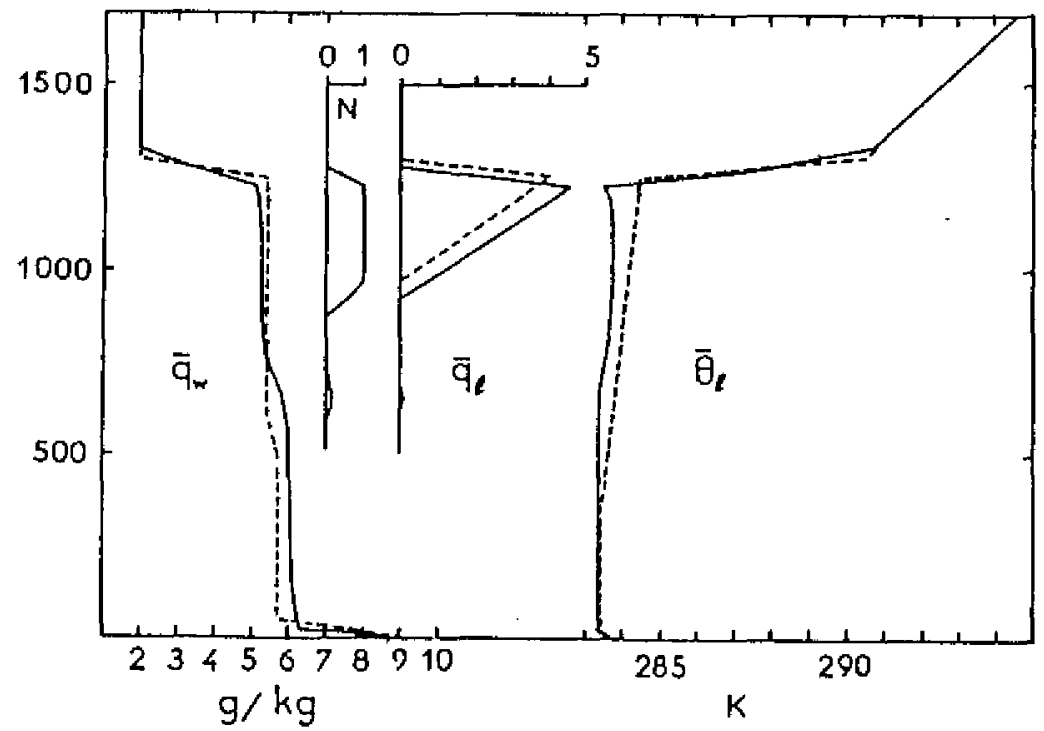

Fig. 5. Computed (solid line) and observed total specific humidity (dashed line), $\bar{q}_{w}$, in Bougeault (1985).

to the vapor mixing, the steepening in the upper part of the cloud disappears.

Profiles of the fluxes of specific humidity ( $\overline{w^{\prime} q_{w}^{\prime}}$, solid line) and liquid water content $\left(\overline{w^{\prime} q_{l}^{\prime}}\right.$, dashed line) at 1500 EST and 0300 EST on Day 33-34 and 34-35 are shown in Figs. 7 and 8 , respectively. Within the subcloud layer (Fig. 7), the 


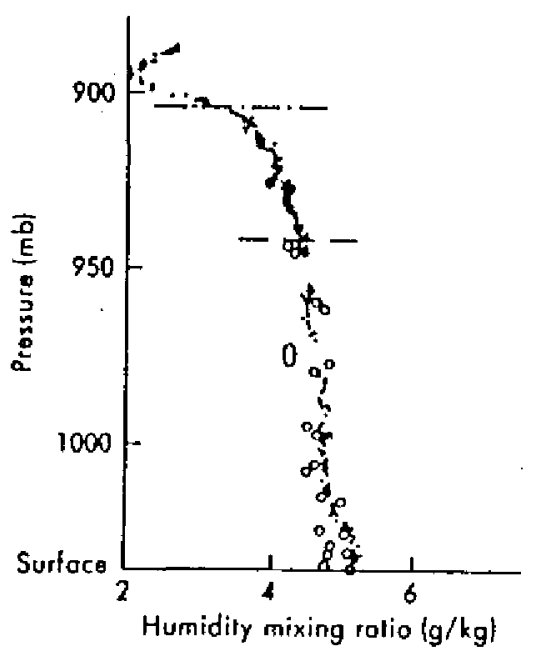

Fig. 6. Observed humidity mixing ratio of the nocturnal stratocumulus in Roach et al. (1982).

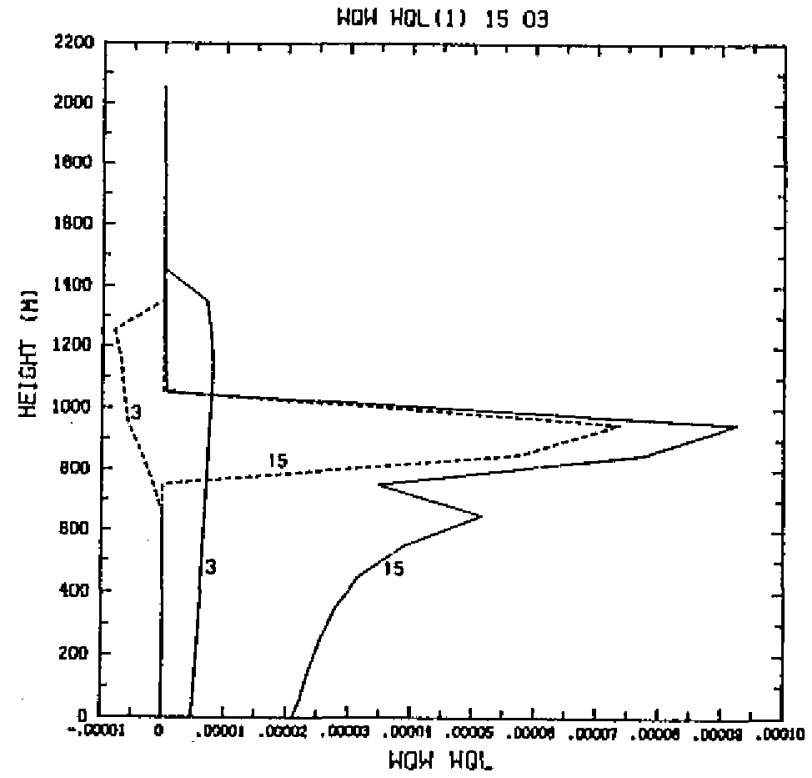

Fig. 7. Profiles of the turbulent fluxes of total specific humidity (solid line) and liquid water content (dashed line) at $1500 \mathrm{EST}$, Day 33 and $0300 \mathrm{EST}$, Day 34 .

$\overline{w^{\prime} q_{w}^{\prime}}$ increases with height, which is similiar to those in cloud-free atmosphere. Above the cloud, the $\overline{w^{\prime} q_{w}^{\prime}}$ can be negligible. During the daytime (1500 EST) the $\overline{w^{\prime} q_{w}^{\prime}}$ is stronger than that during the night (0300 EST) because of convection. The moisture was carried upward to the cloud top. Hence, the value of $\bar{q}_{w}$ would become uniform in the whole convective layer as time went on. The kinks in 


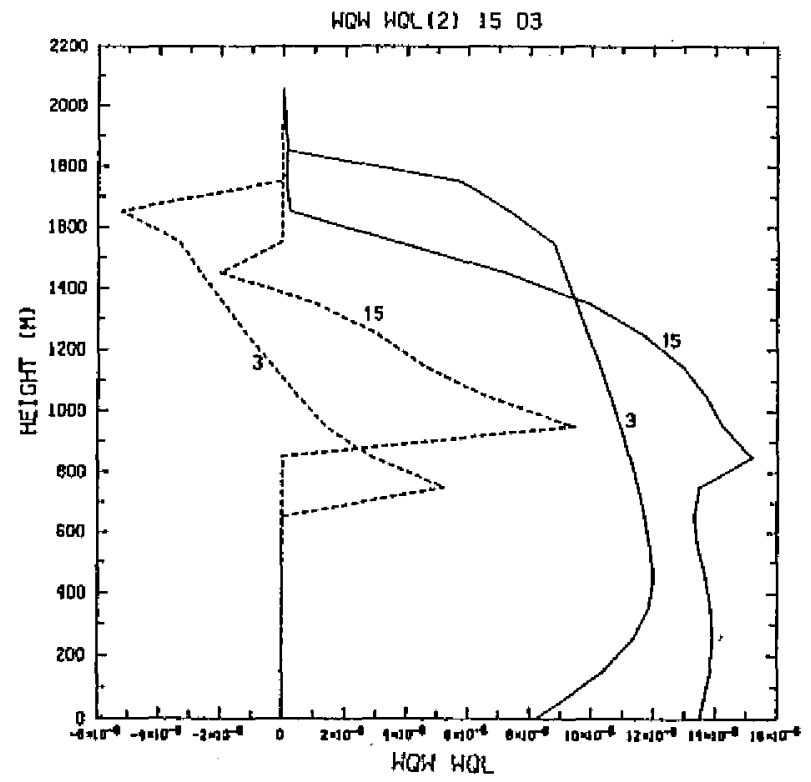

Fig. 8. Same as Fig. 7 except at 1500 EST, Day 34 and 0300 EST, Day 35.
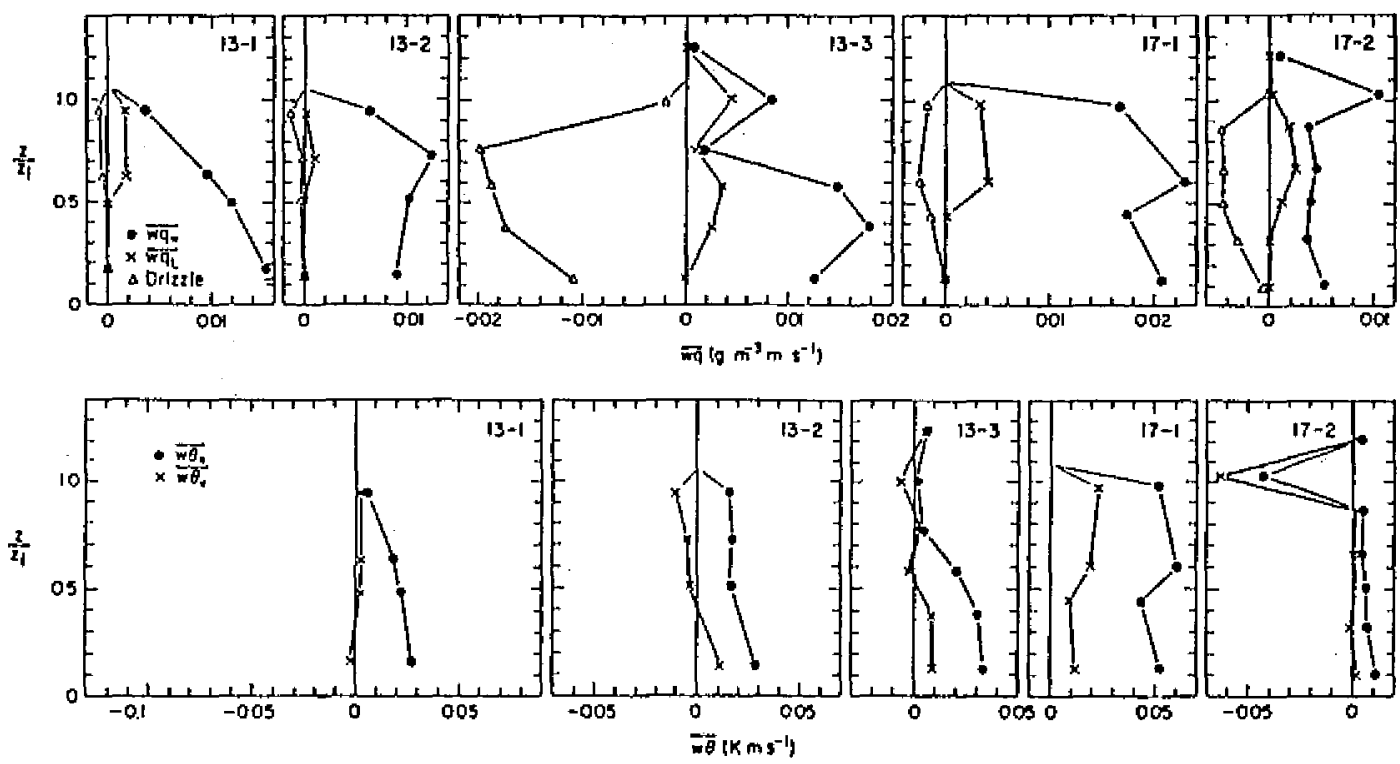

Fig. 9. Observed profiles of vertical turbulent fluxes of water and potential temperature in the marine stratocumulus (from Brost et al. 1982).

the curve of $\overline{w^{\prime} q_{w}^{\prime}}$ near the cloud base (Fig. 7) are only transitional phenomena. Unlike in Fig. 7, the maximum $\overline{w^{\prime} q_{w}^{\prime}}$ at 1500 EST on Day 34 and 0300 EST on Day 35 (Fig. 8) does not occur just below the cloud top. A similar shape is also 
found in Chen and Cotton (1983), Bougeault (1981, 1985), and the observation of Case 13-2 in Brost et al. (1982) (see Fig. 9).

As in Experiment 2 of Chen and Cotton (1983), there are negative value of $\overline{w^{\prime} q_{l}^{\prime}}$ in our simulated results. The $\overline{w^{\prime} q_{l}^{\prime}}$ is obtained by the difference of two terms which are larger than $\overline{w^{\prime} q_{l}^{\prime}}$. As indicated by Chen and Cotton (1983), positive $\overline{w^{\prime} \theta_{e}^{\prime}}$ tends to produce negative $\overline{w^{\prime} q_{l}^{\prime}}$. The structure of $\theta_{e}$ is slightly unstable below the inversion because of the use of eddy-coefficients. A slightly large $\overline{w^{\prime} \theta_{e}^{\prime}}$ within the cloud layer will result in negative $\overline{w^{\prime} q_{l}^{\prime}}$.

\section{c. Radiative cooling rate}

Fig. 10 shows the vertical profiles of the long- and short-wave radiative warming or cooling rates at 1500 EST on Day 34 and 0300 EST on Day 35. At $1500 \mathrm{EST}$, the value of the cosine of the solar zenith angle is 0.48 . It is noted that the short-wave warming occurs mainly in the upper $100 \mathrm{~m}$ ( 1 grid point) of the cloud. This is consistent with the penetrative distance in Stephens (1978).

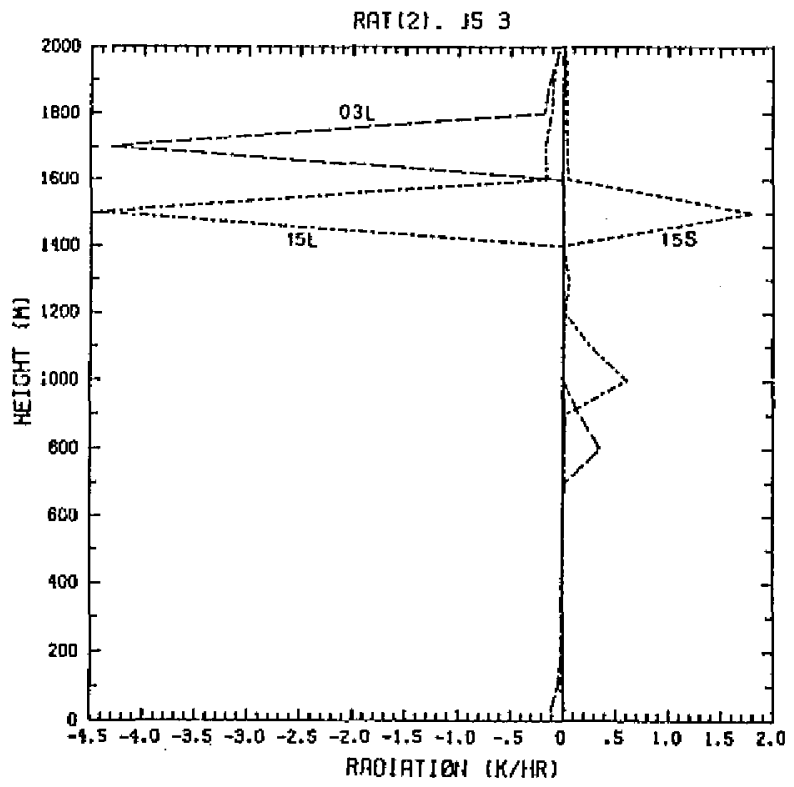

Fig. 10. The vertical profiles of long- and short-wave radiative cooling rate $\left(K h r^{-1}\right)$ at 1500 EST, Day 34 and 0300 EST Day 35.

There is a strong long-wave radiative cooling rate near the cloud top and a relatively small long-wave radiative warming rate near the cloud base. The long-wave radiative cooling rate near the cloud top at 1500 EST and 0300 EST are $4.4 K_{h r^{-1}}$ and $4.3 K K^{-1}$, respectively, which are close to the results in Chen and Cotton (1983) (about $100 \mathrm{~K} \mathrm{day}^{-1}$ or $4.2 \mathrm{~K} \mathrm{hr}^{-1}$ ). The short-wave radiative warming rate near the cloud top at 1500 EST is $1.8 \mathrm{~K} \mathrm{hr}^{-1}$, which 
is also close to the results in Chen and Cotton (1983) (about $35 K \mathrm{day}^{-1}$, or $1.5 \mathrm{~K} \mathrm{hr}^{-1}$ ). During the daytime (1500 EST), the long-wave radiative cooling is partially compensated for by the short-wave radiative warming. The observational cooling rate is about $-5 \mathrm{~K} \mathrm{hr}^{-1}$ to $-10 \mathrm{~K} \mathrm{hr}^{-1}$ within $50 \mathrm{~m}$ of the cloud top (Roach et al, 1982), which indicates that a better resolution may be required in the future in order to obtain a stronger cooling rate near the cloud top.

\section{d. Turbulent kinetic energy budget}

The computed contributions of TKE at 1200 EST, Day 34 (Fig. 11) are similar in shape to those in Deardorff (1980) (Fig. 12) and Bougeault (1985). In the lower part of the subcloud layer, the dissipation rate (D) and the buoyancy production (B) are the dominant terms. In the cloud layer, the buoyancy production is balanced by the dissipation and the transport term $(\mathrm{T})$. The transport term also plays an important role just above the cloud top and at the cloud base, where the turbulence is maintained by the transport term against the dissipation and the negative buoyancy production. Brost et al. (1982) indicated that, in the observation of marine stratocumulus, the dissipation usually decreased with height through out most of the boundary layer, but sometimes had a peak in the inversion. This peak is found in Figs. 11 and 12, and Bougeault (1985). Deardorff (1980) 'pointed out that a slightly negative value of $T$ occurs above the capping inversion, resulting in a large residual imbalance, which is probably due to truncation errors. Because the cloud in this study is higher than that in Deardorff, the heights of peak of $D, T$ and $B$ are higher in Fig. $11(1.4 \mathrm{~km})$ than those in Fig. $12(1.1 \mathrm{~km})$.

\section{e. Variation of cloud}

Fig. 13 presents the hourly variations of specific liquid water content. After adjusting temperature and moisture at 1200 EST on Day 33, the cloud appear and grow rapidly until $1800 \mathrm{EST}$, because the depth of the mixed layer grows drastically. The cloud grows higher continually, but slowly, due to radiative cooling at the cloud top. On the other hand, the height of the cloud base increases with time during the daytime, but decreases with time at night. Because of the surface heat flux, during the daytime the planetary boundary layer develops continuously. Consequently, the height of the cloud base increases with the increase of temperature in the mixed layer. The highest cloud base occurs at 1700 EST on both Day 33 and 34 .

After sunset, the surface heat flux ceases or becomes negative. Also, the long-wave radiative cooling is not compensated for by the short-wave radia- 


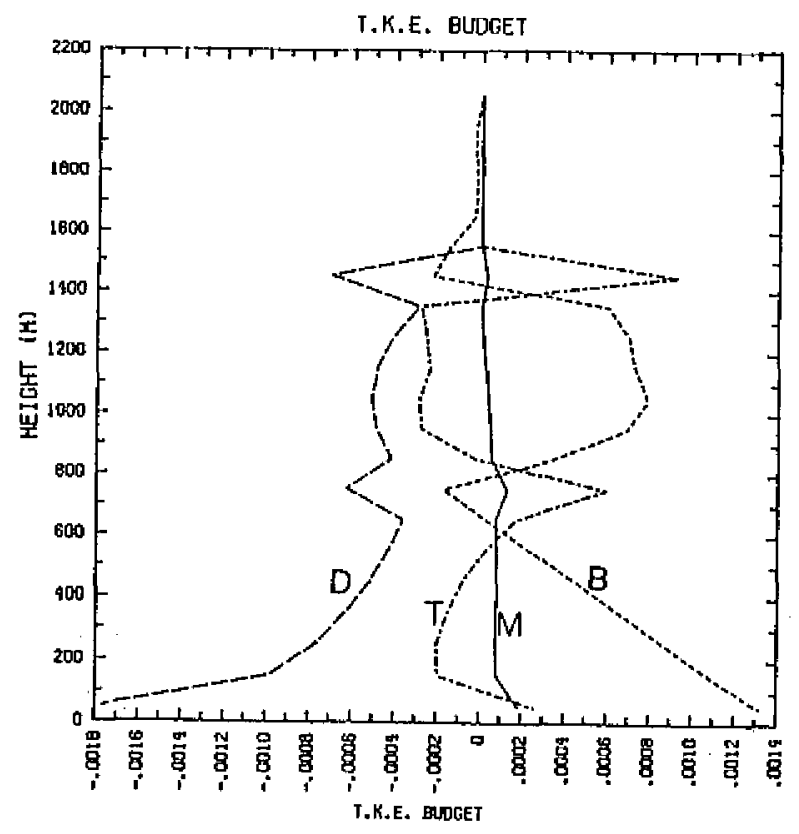

Fig. 11. Budget of the turbulent kinetic energy $\left(m^{2} s^{-3}\right)$ at 1200 EST, Day 34: $B$, buoyancy production; $T$, transport term; $D$, dissipation term; $M$, shear production.

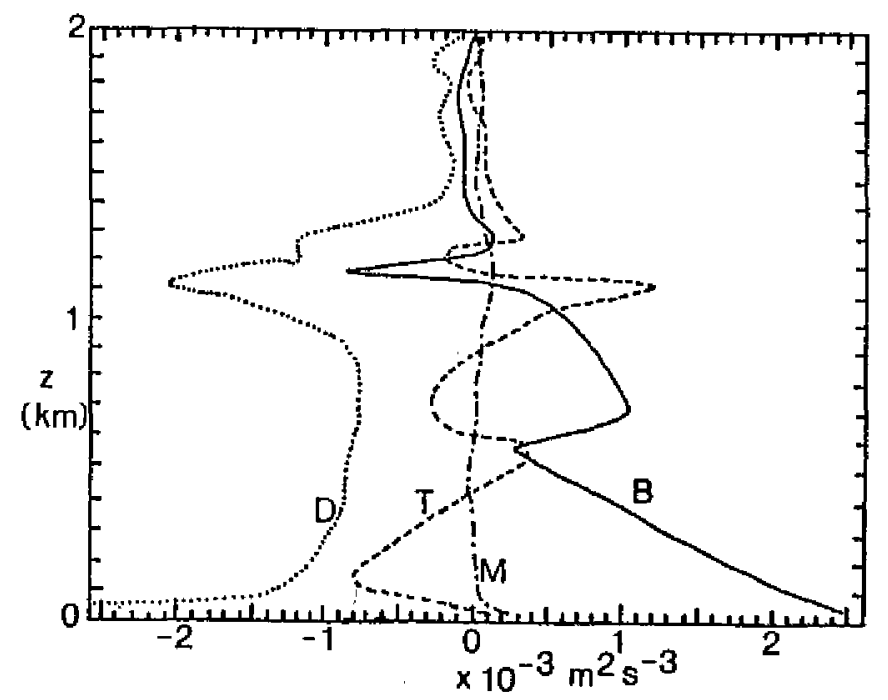

Fig. 12. Budget of the turbulent kinetic energy in Deardorff (1980). The turbulent and pressure redistributions have been combined together and shown by curve $\mathrm{T}$.

tive warming. The stronger radiative cooling produces more liquid water content and a latent heat release, which enhances the turbulence inside the cloud. Therefore, the cloud grows both upward and downward. It is also found that 


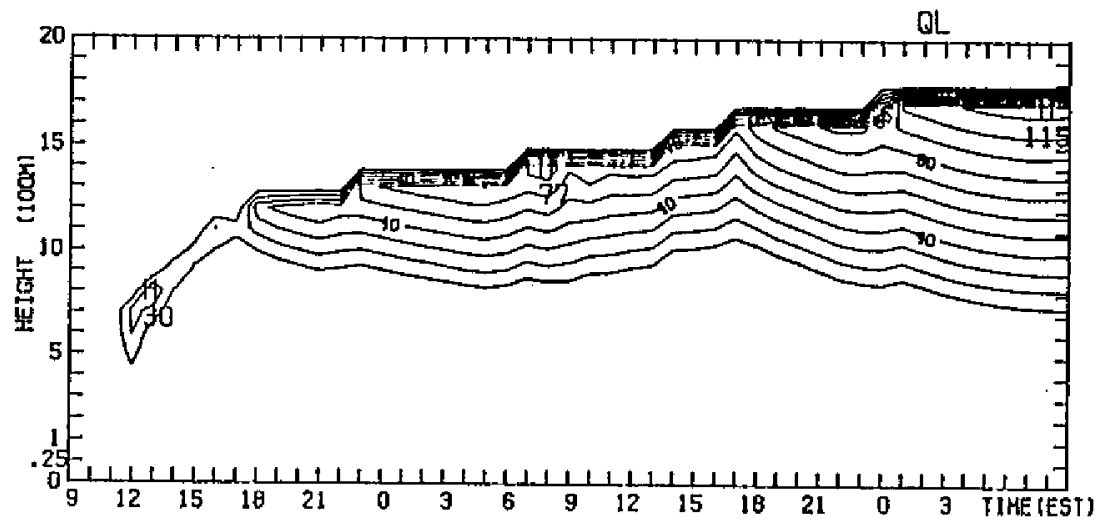

Fig. 13. Hourly variation of the liquid water content $\left(10^{-5} \mathrm{~kg} \mathrm{~kg}^{-1}\right)$ from 0900 EST, Day 33 to 0900 EST, Day 35.

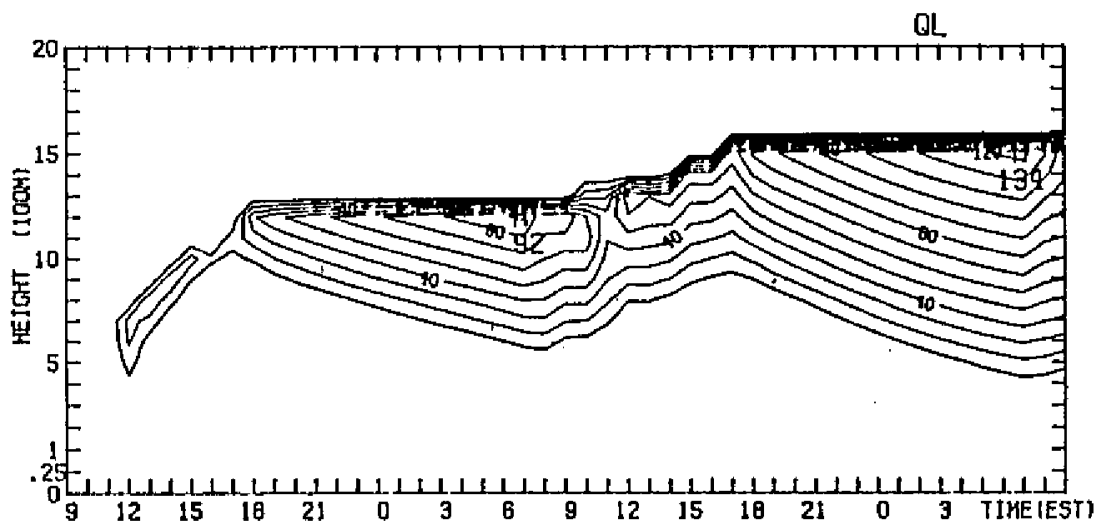

Fig. 14. Same as Fig. 13 except the value of 1.316 in length scale equation is replaced by 0.76 .

the cloud top develops very fast without a large-scale subsidence. As suggested by Roach et al. (1982), a strong subsidence $\left(2 \sim 4 \mathrm{~cm} \mathrm{~s}^{-1}\right)$ is usually required to maintain a constant cloud top during the night. In this study, the subsidence is very small $\left(\sim 0.2 \mathrm{~cm} \mathrm{~s}^{-1}\right)$; however, it is very likely that the cloud top grows.

In order to test the effects of the imposed mixing length scale, the value of 1.316 in the length scale equation, $l_{s}=1.316 \bar{E}^{1 / 2}\left\{\left(g / \theta_{0}\right)\left(-\overline{w^{\prime} \theta_{v}^{\prime}} / K_{h}\right)\right\}^{-1 / 2}(\mathrm{Wu}$ and Sun, 1990, Eq.(10)), is replaced by 0.76. Both the cloud-free and cloudy cases are simulated again. Except for the $\bar{q}_{l}$ field in the cloudy case (see Fig. 14 ), the results are not substantially different from those obtained previously. Unlike in Fig. 13, during the night, the height of the cloud top remains constant because of the decrease of the mixing and entrainment there. As the turbulent mixing increases, so does the height of the cloud top, because more liquid water can be transported to the cloud top or even beyond. 


\section{f. Surface temperature}

The computed hourly variations of surface soil temperature $\left(T_{g}\right)$ and the temperature $\left(T_{1.2}\right)$ at the screen height are shown in Fig. 15. The observed temperature $\left(T_{o b s}\right)$ at the screen height in the Wangara Experiment (cloud free) is also shown. The kinks of $T_{g}$ and $T_{1.2}$ at $1300 \mathrm{EST}$ on DAY 33 are caused by adjusting the temperature and moisture at $1200 \mathrm{EST}$. As for the cloud-free case (Wu and Sun, 1990), $T_{g}$ and $T_{1.2}$ decrease rapidly after sunset and increase again after sunrise of the next day. Due to the coverage of cloud, short-wave radiative flux is partially shut off. Therefore, the amplitudes of $T_{g}$ and $T_{1,2}$ are smaller than those in the cloud free case. Also, the amplitudes of $T_{g}$ and $T_{1.2}$ on the second day are smaller than those in the first day because of thicker cloud.

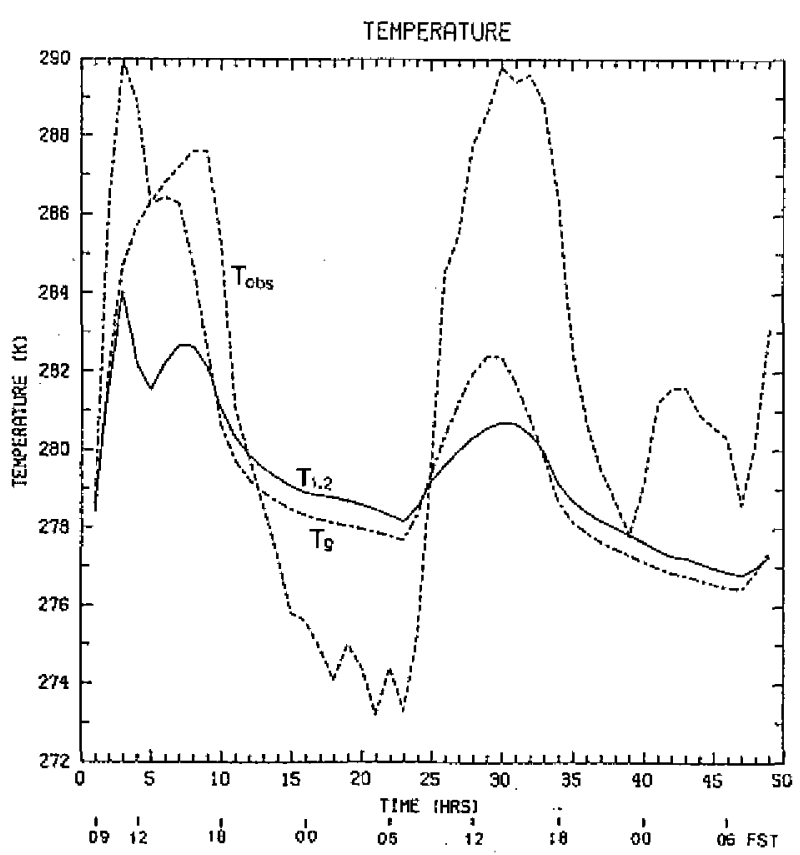

Fig. 15. Hourly variations of the temperatures: dashed-dotted line, predicted ground surface soil temperature $\left(T_{g}\right)$; solid line, predicted temperature $\left(T_{1.2}\right)$, at screen height $(1.2 \mathrm{~m})$; dashed line, observed temperature $\left(T_{\text {obs }}\right)$, at screen height in the Wangara Experiment.

\section{SUMMARY}

A simple one-dimensional ensemble average PBL model is applied to study the evolution of PBL for the cloudy situation. The prognostic variables are equivalent potential temperature, specific humidity, two horizontal wind com- 
ponents, and turbulent kinetic energy. The eddy-coefficient relations are employed to calculate the eddy fluxes. The ground surface soil temperature and moisture are predicted by a force restoring method. Also, the methods in Chen and Cotton (1983) are adopted to parameterize the atmospheric radiation.

The observed data at 0900 EST on Day 33 in the Wangara Experiment are used to run for the first 3 hours (to $1200 \mathrm{EST}$ ). After that time, the moisture and temperature are modified in order to initiate a cloud layer. Then, the model is integrated for 45 hours. The simulated mean fields and eddy fluxes are comparable with other higher-order model and observations.

During the daytime, the linear decreases of $\overline{w^{\prime} \theta_{v}^{\prime}}$ with height in the lower convective layer are consistent with a uniform change of mean temperature within the subcloud layer. A slightly negative heat flux exists near the cloud base, which occurs in Sommeria (1976) and Bougeault (1985). Primarily, attributed to the latent heat release and enhanced by the strong radiative cooling, a substantial positive heat flux exists in the cloud layer. A negative buoyancy flux exists just above the cloud top because of entrainment and diabatic cooling, as in results of Sommeria (1976), Deardorff (1980), Chen and Cotton (1983), and Bougeault (1985).

During the night (0300 EST), the heat flux near the surface becomes negative. Also, like the daytime results, a positive heat flux exists inside the cloud and a negative heat flux exists just above the cloud top.

Acknowledgements. Part of this work was supported by the National Science Council and the National Science Foundation (U.S.) under grants ATM8313418 and 8611729 .

\section{REFERENCES}

Bhumralkar, C. M., 1975: Numerical experiments on the computation of ground surface temperature in an atmospheric general circulation model. J. Appl. Meteor., 14, 1246-1258.

Blackadar, A. K., 1976: Modeling the nocturnal boundary. Proceedings of the Third Symposium on Atmospheric Turbulence, Diffusion and Air Quality, Amer. Meteor. Soci, 46-49.

Bougeault, P., 1981: Modeling the trade-wind cumulus boundary layer. Part II: A higher-order one-dimensional model. J. Atmos. Sci., 38, 2429-2439. , 1985: The diurnal cycle of the marine stratocumulus layer: a higher-order model study. J. Atmos. Sci., 42, 2826-2843.

Brost, R. A., J. C. Wyngaard and D. H. Lenschow, 1982: Marine Stratocumulus layers. Part II: Turbulence budget. J. Atmos. Sci., 39, 818-836.

Businger, J. A., J. C. Wyngaard, Y. Izumi and E. F. Bradley, 1971: Flux- 
profile relationships in the atmospheric surface layer. J. Atmos. Sci., 28, 181-189.

Caughey, S. J., B. A. Crease, and W. T. Roach, 1982: A field study of nocturnal stratocumulus. Part II: Turbulent structure and entrainment. Quart. J. Roy. Meteor. Soc., 108, 125-144.

Chen, C., and W. R. Cotton, 1983: A one-dimensional simulation of the stratocumulus-capped mixed layer. Bound.-Layer Meteor., 25, 289-321.

Clark, R. H., D. G. Reid and A. J. Troup, 1971: The Wangara experiment: Boundary layer data. Tech. paper 19. CSIRO, Australia.

Deardorff, J. W., 1978: Efficient prediction of ground surface temperature and moisture, with inclusion of a layer of vegetation. J. Geophys. Res., 83, 1889-1903.

, 1980: Stratocumulus-capped mixed layers derived from a three-dimensional model. Bound.-Layer Meteor., 18, 495-527.

Fravalo, C., Y. Fouquart and R. Rosset, 1981: The sensitivity of a model of low stratiform clouds to radiation. J. Atmos. Sci., 38, 1049-1062.

Kahn, P. H., and J. Businger, 1979: The effect of radiative flux divergence on entrainment of a saturated convective boundary layer. Quart. J. Roy. Meteor. Soc., 105, 303-306.

Kraus, H., and E. Schaller, 1978: Steady-state characteristics of inversion capping a well-mixed planetary boundary layer. Bound.-Layer Meteor., 14, 83-104.

Lilly, D. K., 1968: Models of cloud-topped mixed layer under a strong inversion. Quart. J. Roy. Meteor. Soc., 94, 292-309.

Paltridge, G. W., 1971: Solar and thermal radiation flux measurements over the east coast of Australia. J. Geophys. Res., 76, 2857-2865.

, 1974: Infrared emissivity short-wave albedo and the microphysics of stratiform water clouds. J. Geophys. Res., 79, 4053-4058.

Platt, C. M. R., 1976: Infrared absorption and liquid water content in stratocumulus cloud. Quart. J. Roy. Meteor. Soc., 102, 533-561.

Randall, D. A., 1980: Entrainment in a stratocumulus layer with distributed radiative cooling. $J$. Atmos. Sci., 37, 148-159.

Roach, W. T., R. Brown, S. J. Caughey, B. A. Crease and A. Slingo, 1982: A field study of nocturnal stratocumulus: I. Mean structure and budget. Quart. J. Roy. Meteor. Soc., 108, 103-123.

Rodgers, C. D., 1967: The use of emissivity in atmospheric radiation circulations. Quart. J. Roy. Meteor. Soc., 93, 43-54.

Schubert, W. H., 1976: Experiments with Lilly's cloud-topped mixed layer model. J. Atmos. Sci., 33, 436-446.

Sommeria, G., 1976: Three-dimensional simulation of turbulent process in an undisturbed trade wind boundary layer. J. Atmos. Sci., 33, 216-241. 
Stephens, G. L., 1978: Radiation profiles in extended water clouds. Part II: Parameterization scheme. J. Atmos. Sci., 35, 2123-2132. , G. W. Paltridge and C. M. R. Platt, 1978: Radiation profiles in extend water cloud, III: Observations, J. Atmos. Sci., 35, 2133-2141.

Sun, W. Y., and C. Z. Chang, 1986: Diffusion model for a convective layer: Part I. Nunerical simulation of a convective boundary layer. J. Climate and Appl. Meteor., 25, 1445-1453. , and Y. Ogura, 1980: Modeling the evolution of the convection planetary boundary layer. J. Atmos. Sci., 37, 1558-1572.

Wu, C. C., and W. Y. Sun, 1990: Diurnal oscillation of convective boundary layer, Part 1: Cloud-free atmosphere, TAO, 1, 23-43.

Wu, C. C., and W. Y. Sun, 1987: Formation and evolution of dryline. Third Conference on Mesoscale Meteorology, Vancouver, Canada, 222-223.

Yamamoto, G., 1962: Direct absorption of solar radiation by atmospheric water vapor, carbon dioxide and molecular oxygen. J. Atmos. Sci., 19, 182-188. 


\title{
對流邊界層之日夜變化 第二部分 有雲大氣
}

\author{
吳清吉 \\ 國立台灣大學大氣科學系 \\ 商文義 \\ 美國普度大學地球和大氣科學系
}

\section{摘 要}

一個簡單的一維總體平均邊界層模式, 用以研究有雲大氣時邊界層的演化。模式中包含

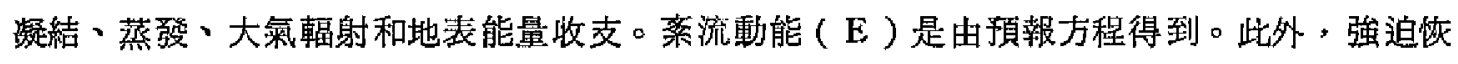
復方法也被利用於預報地表的溫度和濕度。

Wangara 實羷第 33 天, 早上 9 時的資料被用作初始場, 積分 3 小時後, 改禁溫度和濕 度場, 以產生雲層。然後, 模式再被積分 45 小時。模欵的平均場和案流通量場性質和其他滈 階亲模式結果相當一致。白天, 在低㕌對流邊界層內妾流熱通量隨高度增加而減少。在雲內 有一主要的案流熱通量最大値存在, 主要是由於潛熱程放和輻射冾却加強所致。夜晚, 近地 大氣的案流熱通量向下, 但是在雲量的最大案流熱通量, 仍然維持着。在雲頂有一问下的案 流熱通存在。 